\title{
LINGUISTICS
}

UDC 81

DOI: $10.17223 / 24109266 / 5 / 1$

\section{ON THE CLASSIFICATION OF LINGUISTIC PHENOMENA OF ASYMMETRY (EVIDENCE FROM THE RUSSIAN AND ENGLISH LANGUAGES)}

\author{
T.V. Antonova \\ I.G. Petrovsky Bryansk State University (Bryansk, Russian Federation). \\ E-mail: antonova.antonova22041973@yandex.ru
}

\begin{abstract}
The article deals with the phenomenon of linguistic asymmetry that involves the erroneous translation of the linguistic units of a source language due to their phonetic similarity with the units of a translation language. The author addresses the problem of similarity and near-identity, using the analysis of several typologies developed by the scientists. The author has worked out a classification which includes: the words that have no identical dictionary meanings; interlingual paronyms - the words that are different both in form and meaning, but are often identified; interlingual synonyms and functional misleading words. When translating the words relating to the group of formal misleading words like "jellyfish" (медуза), "ladybird BE" or "ladybug AE" (божья коровка), the translation error occurs due to the combined process including both the equivalent translation and onomatopoeia. Therefore, onomatopoeia is not the only cause of the process of misinterpretation. The differences between the interlingual synonyms under analysis let us develop the typology based on the differences in the conceptual content according to the plane of content and to the plane of expression. According to the plane of content, we can highlight the following features of the interlingual synonyms: both similarity and difference in meanings; generic meanings in one language but specific in the other language; differences relating to culture-specific concepts; differences in stylistic characteristics; differences in lexical combinability. According to the plane of expression, they can be both similar and different in their extensions. The last group consists in the words with different meanings. However, they belong to the same semantic field. These functional misleading words clearly show the following logical-semantic relations: a causal connection; similar sizes, similar functioning, similar manufacturing processes and so on. In the end, the author presents the summary typology using various illustrative materials.
\end{abstract}

Keywords: mistakes in translation; linguistic asymmetry; similarity; nearidentity; typology.

\section{Introduction}

Translation is one of the oldest human activities, and it emerged when a need for communication arose. The study of linguistic aspects of transla- 
tion has always had an important place in linguistics in ancient as well as in modern society. In our view, the phenomenon of linguistic asymmetry or "faux amis" is one of the most interesting phenomena. The phenomenon is known to imply a false translation of the linguistic units of a source language due to the phonetic similarity with the units of a translation language. Moreover, false translation may occur as a result of graphic, grammar or semantic identification. We make the largest number of mistakes when translating international words, which can abundantly be found in media texts. This problem may interest translators, and those who learn a foreign language as well.

V.V. Akulenko, R.A. Budagov, K.H.M. Gottlieb, N.K. Garbovskiy and I.N. Kuznetsova did much to classify the phenomena of linguistic asymmetry. Let us refer to several typologies developed by the scientists. This analysis will help us develop a single classification.

\section{Methods}

To reach the purpose we have to apply the following methods to our research:

- a heuristic method refers to the collection of the language data;

- we need a descriptive method to present the data in a proper way;

- an explanatory description is used to show typological regularities;

- a comparative method is necessary for revealing common and specific features of similar language phenomena.

\section{Research}

V.V. Akulenko rightly observes that misinterpreted words can mislead not only those who have just started learning a foreign language and do not speak it well yet. In fact, as the researchers of this lexical categories note, the situation is opposite: the bulk of these words (except for a few obvious cases that are primarily related to homonymy) is dangerous for the individuals who confidently and almost satisfactorily use the language although they have not reached the level of adequate unmixed bilingualism yet. Therefore, they falsely identify some elements of the foreign and native languages.

One cannot help agreeing with the opinion of the scientist, so there are numerous semantic calques and violations of lexical compatibility or stylistic correspondence not only in the way of using a foreign language, but also in translations and even in their original usage [1:371-372].

V.V. Akulenko comes to the correct idea that differences in pairs of misleading words may be the following. There are significant differences in the conceptual content due to the specific classifications of phenomena, properties, and relations of the objective world which are characteristic of the semantics of every language. For example, compare "intelligence" - 
"the ability to think, understand, and learn things well; information that is gathered by the government or the army about their country's enemies and their activities" [2] with "интеллигенция" - "intellectuals that have education and expertise in various fields of science, technology and culture; social class of people engaged in such work" [3].

In addition, the author of the above mentioned article emphasizes that we have to take into account possible differences in stylistic characteristics of these words. For example, compare "manuscript" - "a handwritten or typed document, especially a writer's first version of a book before it is published; an old document that was written by hand on paper or parchment before printing was invented" with "манускрипт" - "(literary) an old document that was written by hand".

V.V. Akulenko mentions that the differences in lexical combinability of Russian words and their English equivalents create significant difficulties in learning foreign languages and in translation as well. For example, the word "situation" - "what is happening in a particular place at a particular time" can be combined with "life-and-death" meaning "extremely important". There is a Russian set expression "вопрос жизни и смерти" in which the word "вопрос" is used. We cannot use the word "ситуаиия" in this context.

Let us refer to the typology worked out by R.A. Budagov "More on the New Editions of Misleading Words Dictionary" [4: 65-68]. The author distinguishes several types of relations: 1) a word has a more general meaning in one language than in the other; 2) a generic meaning in one language, a specific one in the other; 3 ) monosemy in one language, polysemy in the other; 4) interlingual stylistic equivalence of words and phrases; 5) a live meaning in one language, an archaic one in the other; 6) free lexical combinability in one language, a restricted one in the other.

Several points of this classification can be exemplified as follows. The word "hymn" means "a religious song that people usually sing in churches". However, it has a more general meaning in Russian - "an official song, a symbol of public or social unities". Apart from this, the word "favourite" "your favourite person or thing of a particular kind is the one that you like the best", has the following meaning in Russian: "a person who receives benefits and advantages from his patron".

What is more, compare the Russian лицей - "1) in pre-revolutionary Russia: a privileged educational institution for men; 2) a secondary school in some countries" - and the English "lyceum" - "1) a hall for public lectures and discussions; 2) an association providing lectures, concerts, and entertainments". The latter has archaic meanings in Am E.

Another author, K.H.M. Gottlieb [5], distinguishes between four types of "faux amis", taking into consideration the nature of the discrepancies in their meanings. The first type includes the words and semantic variants that 
represent different objects and phenomena in two languages. The second type comprises the words and semantic variants that indicate similar objects and concepts but different ones in the shades of their meanings. The words with the same meaning but different in connotation or restricted in their use (under the appropriate labels) belong to the third type. The fourth type covers the words identical in both languages, but we can consider them as equivalents only in certain phrases or compound words.

For example, a word can have a figurative meaning in one language but it cannot have the same figurative meaning in the other. Only direct meanings of such words can coincide in this case:

Eng. "abortive" - "not finished and therefore not successful"; Rus. абортивный - "immature”.

Eng. "abrasive" - "1) behaving in the way that seems rude to other people, because you say what you think even if it is not nice; 2) having a rough surface that can be used to rub and clean other surfaces"; Rus. aбpaзивный - "having a rough surface that can be used for grinding, polishing and sharpening".

Eng. "imperial" - "relating to an eтpire"; Rus. имперский - "relating to an empire; (figurative) typical of a big power, with the spirit of superiority over other peoples and states". E.g. Imperial manners and ambitions.

Following the authors who admit the relations of similarity and nearidentity on the basis of onomatopoeia or similar functions in both languages as a cause of translation mistakes, N.K. Garbovskiy puts forward the idea about the existence of language universals, i.e. universal perception and categorical reflection of the world. He asserts that such universals give rise to the phenomenon of interlingual asymmetry, which can be considered within the framework of translation interference.

The author tries to answer the question: "Is the problem of "faux amis" really relevant in the theory of translation?" Actually, the problem exists and the problem is quite complex. The slighter the differences between misleading words are, the more complex the problem becomes. Moreover, dictionaries are not always helpful in distinguishing these differences especially when we deal with polysemous words. Finally, the relations of similarity influence an interpreter in a psychological way. They do not stimulate him or her to consult a dictionary.

N.K. Garbovskiy puts forward the following classification. There are relationships between the misleading words which do not contain any common meaning. On the face of it, they cannot comprise equal concepts. However, some misleading words which are partly asymmetric can present the concepts of equal extension. They are primarily interlingual synonyms. The concepts represented by them are in overlapping relationship if their extensions have common meanings as well as different ones. There are also logical relations when the extension of one notion is completely "absorbed" by 
another one. This is evident if we compare the words containing generic notions (hyperonymy) with the words denoting specific concepts or proper names (hyponyms) [6].

These points can be illustrated by differences in extensions. Let us compare the misleading words which are partly asymmetric in their meanings: Eng. "intrigue" - "a secret plan to harm or to cheat someone, or the process of making such a plan" - and Rus. интрига - "a secret plan to harm or to cheat someone, or the process of making such a plan; way of constructing a complex plot in a novel; (archaic) love affair".

Studying the process of lexical interference, another author, I.N. Kuznetsova [7], indicates interlingual paronyms (when similar words are mixed in communication, leading to the emergence of "faux amis"). She suggests her own semantic typology. Misleading lexical units are divided into three semantic classes: synonymous, contact and distant words. Synonymic paronyms do not coincide in all the meanings. Contact words do not have common meanings, but they can have functional similarity (metaphorical or metonymic); namely, they can belong to the same semantic field. Distant words have no similar meanings. They can have functional similarity. But, when they have no such similarity, a mix-up, motivated by sound, similarity is purely formal.

We cannot but support the above mentioned ideas. In addition, we put forward our own classification of misleading words. The illustrative material is taken from the British media and dictionary entries.

1. Formal misleading words. The incorrect translation of such words is due to their phonetic similarity: "Iraq's top cleric, Grand Ayatollah Ali alSistani, has called on his compatriots to unite to confront the "big danger" posed by Islamic State militants, and said politicians who cling to their posts are making a "grave mistake", piling pressure on Prime Minister Nuri alMaliki to drop his bid for a third term" [8]. The word "compatriot" can be translated as "соотечественник" but not as "патриот".

We would also like to dwell on some compound words. For example, when translating the words like "jellyfish" (медуза), "ladybird" $\mathrm{Br} E$ or "ladybug" Am E (божья коровка), the mistake occurs if we apply the equivalent translation to each part of these words. Furthermore, the error may occur when translating such words as "landlord / landlady" (арендодатель, хозяин(йка) сдаваемой в наем квартиры, домовладелеи) or "station-wagon" Am E (автомобиль-универсал). It takes place due to the equivalent translation and onomatopoeia. Therefore, onomatopoeia is not the only reason for the mix-up.

2. Interlingual paronyms. Such pairs of words as "leaning" and "learning" that differ both in their form and meaning are often mixed up by students: "However, his critics accuse him of having an abrasive style and Islamist-leanings" [9]. 
3. Interlingual synonyms.

1) Differences in the plane of content:

a) both similarity and difference in meanings: "Outrage as jobless offered taxpayer-funded tattoo art classes to get them off the dole" [10]. Compare "dole" meaning "money that people who do not have a job get from the government; a power that some people believe controls everything that happens in their lives" and the Russian word "доля" meaning "one of the pieces that something consists of; a power that some people believe controls everything that happens in their lives".

b) a generic meaning in one language, a specific one in the other: "But their 90-minute set at a sold-out Islington Assembly Hall put meat on the bones of this modest recorded material: the quaintly optimistic Get Low morphed into a defiant folk anthem, profundity was borne out of Man On Wire's saccharine Sixties pop and beefy percussion from drummer Rob Steadman reinvigorated On the Rocks, which was preluded by field recordings of Antarctica's humpback whales" [8]. The English word "assembly" means "a part of government consisting of people who have been elected to make laws; a meeting of people who represent different parts of a large organization; the process of building something by putting all its parts together”. The Russian “ассамблея” only has specific meanings, i.e. "a meeting of people who represent any international organization; a ball during the reign of Peter I".

c) differences in the interpretation of culture-specific concepts: "The bill for the "design your own tattoo" sessions will be paid from the budget of an anti-poverty programme launched by the Labour-run Welsh Government" [10]. "Session" can be translated as "сессия" when it relates to a formal meeting of an institution such as a parliament or a court. This example implies "design your own tattoo" classes.

d) differences in stylistic characteristics that include differences in evaluative and emotional connotations concerning temporal and regional limitations in the use of words: "The UK has edged up the global rankings in a major annual survey by the World Economic Forum (WEF)" [9]. "Forum" in the meaning of "an organized event or meeting at which people discuss something” is stylistically neutral. The Russian word "форум” meaning "a large meeting of a group of people" has the label "very formal".

e) differences in lexical combinability: "The leading economies in the index all possess a track record in developing, accessing and utilising available talent, as well as in making investments that boost innovation" [9]. "Utilise" meaning "to use something" can be combined with the word "talent”. We can say "утилизировать производственные отходыl" in the Russian language, but we cannot say “утилизировать талант”.

2) Differences in the plane of expression:

a) unequal extensions: "The role will be his main job but his roster will take into account the duties and responsibilities he will continue to un- 
dertake on behalf of the Queen" [11]. Let us compare the words "role" and "роль". "Role" - "1) the purpose or influence of someone or something in a particular situation; 2) the character played by a particular actor in a film, play etc." "Роль" - "1) the artistic image created by a playwright in a play or a play script and played by a particular actor in a film, play; 2) someone's unusual behaviour; 3) the words that an actor says in a performance; the purpose or influence of someone or something in a particular situation".

b) equal extensions: "His critics say the move will make him increasingly authoritarian" [9]. "Authoritarian" is used in the meaning of "controlling everything and forcing people to obey strict rules and laws". The Russian word "авторитарныци" is used in the same meaning. Their extensions are the same, whereas the latter has the label "literary". In other words, the scopes of the concepts are the same; consequently, the differences are stylistic.

4. Functional misleading words: "The UK wins plaudits for adopting technology to enhance productivity and for its general business environment" [9]. The English word "adopt" meaning "to decide to start using a particular idea, plan, or method" and the Russian word "aдаптировать" meaning "to change something slightly in order to make it better, more accurate, or more effective" have different meanings while the semantic field they belong to is the same.

Apart from this, while studying the problem, we have made our own observations regarding the functional misleading words that might help better understand the phenomenon of "faux amis".

Functional misleading words have no similar meanings, but, when comparing them, some logical-semantic relations may be noted:

1) a causal connection. Let us compare the meaning of the adjective "canicular" - "hot days (in July or August)" with "каникулярный" - "during holidays in summer; during holidays in summer (relating to Parliament)": “...we've got canicular summers, with Temperature sometimes over $40{ }^{\circ} \mathrm{C} "[9]$.

2) similar sizes. Compare "cabin" - "a small simple wooden house in the mountains or in a forest" with the Russian word "кабина" - "a small room for particular purpose": "My search for the perfect log cabin certainly did not lack clarity of purpose" [12].

3) similar functioning. Compare "catapult" - "an object that children use for firing stones. It consists of a stick in the shape of a " $Y$ " with a thin band of rubber across the top; a large weapon used in the past for firing heavy stones; a piece of equipment on a ship used for sending aircraft into the air" with the Russian word "катапульта". The latter doesn't have the meaning of "an object that children use for firing stones", but it corresponds to "a large weapon used in the past for firing heavy stones; a piece of 
equipment on a ship used for sending aircraft into the air": "The simplest catapult is an elastic band stretched between your V-sign fingers (though some argue for the greater strength of the index finger and thumb) " [12].

4) similar manufacturing processes. Compare "fabric" - "cloth, especially when it is used for things such as clothes or curtains" with the Russian word "фабрика" - "a building or group of buildings where large quantities of goods are produced using machines": "You've bought your sewing machine, and now you need some fabric” [12].

\section{Conclusion}

Thus, the category of "faux amis" is a very complicated phenomenon that deals with interlingual asymmetry. Therefore, if a translator has a good knowledge of it, he or she is likely to use the right equivalent in the translation.

Based on the two planes linguistic units can be considered in, this typology helps work out further outlines and principles that can be applied to the research of "faux amis".

\section{References}

1. Akulenko, V.V. (1969) More on Misleading Words. In: English-Russian and RussianEnglish Dictionary of Misleading Words. Moscow. pp. 371-372.

2. Müller, V.K., Dashevskaya, V.L., Kaplan, V.A. \& others. (2001) Modern English-Russian Dictionary. Moscow: Russky Yasyk Publishers. 880 p.

3. Ozhegov, S.I., Shvedova, N.Yu. (2007) Explanatory Dictionary of the Russian Language. Moscow: OOO A TEMP Publishers. 944 p.

4. Budagov, R.A. (1970) More on the New Editions of Misleading Words Dictionary. $A N$ SSSR Publishers. Ser. "Literature and Language". 29 (1). pp. 65-68.

5. Gottlieb, K.H.M. (1985) Dictionary of Misleading Words. Moscow: Russky Yasyk Publishers. $160 \mathrm{p}$.

6. Garbovskiy, N.K. (2004) Translation Theory. Moscow: Moskovsky Universitet Publishers. $544 \mathrm{p}$.

7. Kuznetsova, I.N. (1998) The Theory of Lexical Interference (A Case Study of the French Language). Author's Abstract. Moscow.

8. The Daily Telegraph [Online]. Available from: http://www.telegraph.co.uk.

9. The $B B C$ [Online]. Available from: http://www.bbc.com.

10. The Daily Express [Online]. Available from: http://www.express.co.uk.

11. The Daily Mail [Online]. Available from: http://www.dailymail.co.uk/ home/index.html.

12. The Guardian [Online]. Available from: http://www.theguardian.com/uk. 